STUDI

FRANCESI

\section{Studi Francesi}

Rivista quadrimestrale fondata da Franco Simone

154 (LII | I) | 2008

Varia

\title{
Maria De Jesus Cabral, Mallarmé Hors Frontières; Des Défis De l'CEuvre Au Filon Symbolique Du Premier Théâtre Maeterlinckien
}

\section{Maria Emanuela Raffi}

\section{(2) OpenEdition \\ Journals}

\section{Edizione digitale}

URL: http://journals.openedition.org/studifrancesi/9312

DOI: 10.4000/studifrancesi.9312

ISSN: 2421-5856

\section{Editore}

Rosenberg \& Sellier

\section{Edizione cartacea}

Data di pubblicazione: 1 juin 2008

Paginazione: 216-217

ISSN: 0039-2944

\section{Notizia bibliografica digitale}

Maria Emanuela Raffi, «Maria De Jesus Cabral, Mallarmé Hors Frontières; Des Défis De l'Euvre Au Filon Symbolique Du Premier Théâtre Maeterlinckien», Studi Francesi [Online], 154 (LII | I) | 2008, online dal 30 novembre 2015, consultato il 11 janvier 2021. URL: http://journals.openedition.org/studifrancesi/9312 ; DOI: https://doi.org/10.4000/studifrancesi.9312

Questo documento è stato generato automaticamente il 11 janvier 2021.

\section{cc) (†) $\odot$}

Studi Francesi è distribuita con Licenza Creative Commons Attribuzione - Non commerciale - Non opere derivate 4.0 Internazionale. 


\title{
Maria De Jesus Cabral, Mallarmé Hors Frontières; Des Défis De l'Cuvre Au Filon Symbolique Du Premier Théâtre Maeterlinckien
}

\author{
Maria Emanuela Raffi
}

\section{NOTIZIA}

MARIA DE JESUS CABRAL, Mallarmé Hors Frontières; Des Défis De l'CEuvre Au Filon Symbolique Du Premier Théâtre Maeterlinckien, Amsterdam/New York, Rodopi, 2007 («Faux Titre»), Pp. 362.

1 Il corposo studio di Maria de Jesus Cabral si propone di accostare le idee teatrali di Mallarmé, legate alla realizzazione di un 'Grand ÆEuvre' di tipo wagneriano, alle prime realizzazioni del teatro simbolista di Maeterlinck. Il composito contesto simbolista occupa la prima parte dello studio («Mallarmé mobile») e costituisce l'evidente sfondo comune delle diverse esperienze letterarie, delle quali l'autrice sottolinea qui in particolare «la dynamique cosmopolite» che mette in comunicazione, spesso attraverso le riviste letterarie, scrittori di diverse nazioni e in particolare francesi e belgi. Mallarmé appare al centro di questi contatti, che vedono fra i frequentatori dei 'Mardis' Verhaeren, Rodenbach, Mockel, Maeterlinck e Fontainas e hanno dato luogo ad una vasta e intensa corrispondenza.

2 La seconda parte dello studio («L'armature dramatique de l'œuvre») vuole ricostruire il percorso di formazione della concezione poetica di Mallarmé, a partire da Hérodiade. Vi è riconosciuta la grande influenza di Poe, che indica a Mallarmé «un principe d'organisation reniant le hasard», principio che Mallarmé seguirà sempre con attenta preoccupazione per la struttura dell'opera, nella quale viene costantemente iscritta la profondità connotativa e sempre misteriosa delle parole. Tuttavia, nonostante questa 
attenzione all'architettura del testo, è solo a partire da Igitur - e poi, naturalmente, nel progetto del 'Livre' - che si può parlare di 'Théâtre', nel senso totalizzante e metafisico in cui Mallarmé intende questa parola, anche se le radici, "le seuil", come scrive la De Jesus Cabral, di questo 'Théâtre nouveau' sono da cercare già in Hérodiade, «personnage éponyme d'une tragédie». Il progetto di un teatro poetico e la difficoltà della sua realizzazione sono del resto evidenti anche nel Faune, che Mallarmé vorrebbe «absolument scénique, non possible au théâtre, mais exigeant le théâtre».

Di questo progetto di teatro poetico, irrealizzato e irrealizzabile e tuttavia attivo nella trasformazione dell'idea di teatro alla fine dell'Ottocento, l'autrice trova tracce evidenti nelle prime opere di Maeterlinck («Pli selon pli: l'interversion paradigmatique de Maeterlinck»). La comune passione per Wagner, il distacco da qualunque funzione mimetica in favore di «une esthétique du dépouillement» e del «mystère poétique», il rifiuto del gusto teatrale dell'epoca costituiscono convergenze profonde fra i due autori e motivano l'entusiasmo di Mallarmé per La Princesse Maleine (1889) e in generale per le prime opere di Maeterlinck, che vogliono far emergere attraverso i silenzi e l'interiorizzazione un linguaggio sepolto dentro di noi in profondità, la parola che ci abita e tuttavia ci sfugge e di cui non abbiamo che «des lueurs momentanées». 